\title{
Physiological and proteomic analyses on artificially aged Brassica napus seed
}

\author{
Xiaojian Yin ${ }^{1}$, Dongli He ${ }^{1}$, Ravi Gupta ${ }^{2}$ and Pingfang Yang ${ }^{1 *}$ \\ 'Key Laboratory of Plant Germplasm Enhancement and Specialty Agriculture, Wuhan Botanical Garden, Chinese Academy of Sciences, Wuhan, China \\ ${ }^{2}$ Department of Plant Bioscience, College of Natural Resources and Life Science, Pusan National University, Miryang, South Korea
}

\section{Edited by:}

Ganesh Kumar Agrawal, Research

Laboratory for Biotechnology and

Biochemistry, Nepal

Reviewed by:

Joshua L. Heazlewood, The

University of Melbourne, Australia Arkadiusz Kosmala, Institute of Plant

Genetics of the Polish Academy of

Sciences, Poland

${ }^{*}$ Correspondence:

Pingfang Yang, Wuhan Botanical

Garden, Chinese Academy of

Sciences, Wuchang Moshan,

Wuhan 430074, China

e-mail: yangpf@wbgcas.cn
Plant seeds lose their viability when they are exposed to long term storage or controlled deterioration treatments, by a process known as seed aging. Based on previous studies, artificially aging treatments have been developed to accelerate the process of seed aging in order to understand its underlying mechanisms. In this study, we used Brassica napus seeds to investigate the mechanisms of aging initiation. B. napus seeds were exposed to artificially aging treatment $\left(40^{\circ} \mathrm{C}\right.$ and $90 \%$ relative humidity) and their physio-biochemical characteristics were analyzed. Although the treatment delayed germination, it did not increase the concentration of cellular reactive oxygen species (ROS). Comparative proteomic analysis was conducted among the control and treated seeds at different stages of germination. The proteins responded to the treatment were mainly involved in metabolism, protein modification and destination, stress response, development, and miscellaneous enzymes. Except for peroxiredoxin, no changes were observed in the accumulation of other antioxidant enzymes in the artificially aged seeds. Increased content of abscisic acid (ABA) was observed in the artificially treated seeds which might be involved in the inhibition of germination. Taken together, our results highlight the involvement of $A B A$ in the initiation of seed aging in addition to the ROS which was previously reported to mediate the seed aging process.

Keywords: Brassica napus, seed aging, controlled deterioration treatments, proteomics

\section{INTRODUCTION}

Successful germination of seeds is a prerequisite for plants to initiate their life cycle and to distribute their progeny, and is largely determined by the seed vigor (Holdsworth et al., 2008; Rajjou et al., 2012). Seed aging is a process which results in delayed germination, reduction in germination rate, and sometimes even a total loss of seed viability (Priestley, 1986). Prolonged storage of seeds induces seed aging which is a major complication in plant germplasm conservation (Garza-Caligaris et al., 2012). In agriculture, the aged crop seeds germinate poorly and negatively affect the seedlings growth and eventually the yield (Ellis, 1992). When stored in uncontrolled conditions, most of the agricultural crops have 1-5 years of seed viability, which is much less when compared to the wild plants. Optimized storage conditions have been proved fruitful in slowing down the rate of seed aging and eventually increasing the seed life span. For orthodox seeds, low temperature and moisture content are helpful (Walters et al., 2005) while high temperature and humidity have been shown to induce and accelerate the seed aging process (El-Maarouf-Bouteau et al., 2011).

Seed aging leads to various cellular and metabolic alterations including loss of membrane integrity, degradation of DNA, reduced primary metabolism and so on (Corbineau et al., 2002; Kibinza et al., 2006; El-Maarouf-Bouteau et al., 2011). Although the mature seeds are physiological quiescent, these could not prevent the production of reactive oxygen species (ROS). The over-accumulation of ROS and its attack on lipids and proteins are supposed to be the major cause of seed aging (Bailly, 2004). ROS result in the peroxidation and degradation of lipids, which eventually damage the integrity of cellular membranes (Lee et al., 2012; Parkhey et al., 2012). Generally, ROS are regarded as the main factor that leads to seed aging during storage (Priestley, 1986). It has been shown that accumulation of hydrogen peroxide is related to the loss of seed viability in sunflower (Bailly et al., 1996; Kibinza et al., 2006). Under stress conditions, ROS promote program cell death (PCD) in both plants and animals (Grant and Loake, 2000; Neill et al., 2002). However, it is still unknown whether the seed aging is also induced by the ROS through the triggering of PCD or not.

Seed aging is highly associated with the storage conditions, however, recent studies have shown that seeds of different plant species show varied rate of seed aging under the same storage conditions (Walters et al., 2005). It is believed that the viability of the seed is determined by its genetic background as well as the storage conditions (Bewley, 1997; Miura et al., 2002; Clerkx et al., 2004). In Arabidopsis, genes involved in flavonoid and tocopherol biosynthesis can contribute to its seed longevity (Debeaujon et al., 2000; Sattler et al., 2004). Furthermore, a dormancy-related gene delayed of germination 1 (DOG1) (Bentsink et al., 2006) and a heat stress responsive transcription factor (Prieto-Dapena et al., 2006) were also found to improve the resistance to aging. Very recent studies verified that 
methionine sulfoxide reductases from Medicago truncatula and PROTEIN L-ISOASPARTYL METHYLTRANSFERASE (PIMT) from Arabidopsis and lotus (Nelumbo nucifera) could enhance the seed vigor and longevity (Oge et al., 2008; Chatelain et al., 2013; Verma et al., 2013). With the advancement in genomics and other large scale "omics" techniques, number of transcriptomics and proteomics studies have been conducted in the last decade in order to identify and characterize the potential biomarkers for the seed aging (Nakabayashi et al., 2005; Rajjou et al., 2008).

Brassica napus is one of the major sources of edible oil all over the world. However, B. napus seeds are harvested in late spring, and their storage go through the summer season, which leads to the loss of their viability. Thus, it is of great practical importance to prevent the loss of seed vigor, which needs to obtain a comprehensive understanding of the mechanisms underlying the seed aging. Unfortunately, study on this topic in B. napus is rather weak. In this study, we exposed the B. napus seeds to high temperature and humidity, and conducted a comparative proteomic analysis of control and artificial aged seeds in order to understand the underlying mechanisms. A lot of differentially accumulated proteins were identified, which were different with previous studies in other plants. Our results provide some new insights on seed aging mechanisms in B. napus.

\section{MATERIALS AND METHODS}

\section{PLANT GROWTH, AGING TREATMENTS AND GERMINATION ASSAYS}

$B$. napus (zhongshuang11) plants were grown in green house under natural light condition in Wuhan, China. The nondormant seeds were harvested in May of each year and used as experimental materials. Freshly harvested B. napus seeds were treated with high temperature and humidity according to Rajjou et al. (2008) with slight modifications. Briefly, seeds were exposed to $40^{\circ} \mathrm{C}$ and $90 \%$ air humidity for different time points $(0,12,24$, and $48 \mathrm{~h}$ ). Seeds stored at room temperature in sealed plastic bag, at dry conditions, for 1 year were used as natural aged seeds.

The untreated and treated seeds were dried in oven at $40^{\circ} \mathrm{C}$ overnight, and then dipped in distilled water at $26^{\circ} \mathrm{C}$ in darkness for germination. The germination rate for each sample was calculated after every $6 \mathrm{~h}$ until there is no more seed germination. For abscisic acid (ABA) treatment and gibberellic acid (GA) recovery experiments, seeds were imbibed with $10^{-8} \mathrm{M} \mathrm{ABA}$ and $10^{-7} \mathrm{M}$ $\mathrm{GA}_{3}$ solutions during germination, respectively. Three biological replicates were performed for each treatment as well as germination assay with 50 seeds in each set of the replicate. The schematic flowchart of the whole experiment is shown in Figure S1.

\section{MEASUREMENT OF ION LEAKAGE, MALONDIALDEHYDE AND HYDROGEN PEROXIDE CONTENT}

The ion leakage was calculated as described previously (Shi et al., 2012), by measuring the relative conductivity of the samples. Briefly, $0.1 \mathrm{~g}$ of seeds at $0 \mathrm{~h}$ of germination for both samples were incubated in $6 \mathrm{~mL}$ of distilled water, for $4 \mathrm{~h}$ at room temperature with constant shaking. After the incubation, the initial conductivity $(\mathrm{C} 1)$ of the solution was measured. Final conductivity (C2) of the solution was measured after boiling the seeds for $30 \mathrm{~min}$ and cooling down the solution to room temperature. REL was calculated as the percentage of conductivity before and after boiling $[(\mathrm{C} 1 / \mathrm{C} 2) \times 100]$ using a conductivity meter (LeiciDDS-307A, Shanghai precision scientific instrument company, Shanghai, China).

The malondialdehyde (MDA) content was measured using a commercial kit (S0131, Beyotime, Nanjing, China) according to the manufacturer's protocol, which is based on the reaction between MDA and thiobarbituric acid to produce a red compound. In brief, $0.2 \mathrm{~g}$ of seeds were homogenized with $2 \mathrm{~mL}$ of ice-cold phosphate buffer and centrifuged at $1600 \times g$ for $10 \mathrm{~min}$ at $4^{\circ} \mathrm{C}$. The supernatant was then mixed with an equal volume of $0.5 \%$ thiobarbituric acid solution. The mixture was boiled for $10 \mathrm{~min}$. After being cooled down to room temperature with water, the mixture was centrifuged at $3000 \times g$ for $15 \mathrm{~min}$ at room temperature. The absorbance of the supernatant was determined at $530 \mathrm{~nm}$. The concentration of MDA was calculated according to standard curve which was generated with known concentrations of MDA.

Measurement of $\mathrm{H}_{2} \mathrm{O}_{2}$ was carried out according to the method described before (Jaw-Neng Lin, 1998). In brief, $0.1 \mathrm{~g}$ of seeds were homogenized in PBS buffer and centrifuged at $12000 \times g$ for $20 \mathrm{~min}$ at $4^{\circ} \mathrm{C}$. The supernatant was mixed with equal volume of $0.1 \%$ titanium sulfate in $20 \% \mathrm{H}_{2} \mathrm{SO}_{4}(\mathrm{v} / \mathrm{v})$, and then centrifuged again at $6000 \times g$ for $15 \mathrm{~min}$ at room temperature. The absorbance of the supernatant was measured at $410 \mathrm{~nm}$. The concentration of $\mathrm{H}_{2} \mathrm{O}_{2}$ was calculated based on the standard curve which was made with a series of $\mathrm{H}_{2} \mathrm{O}_{2}$ solutions with known concentration. All the measurements were conducted for three biological replicates.

\section{MEASUREMENT OF ABSCISIC ACID CONTENT}

ABA concentration was measured using a derivatization approach coupled with nano-LC-ESI-Q-TOF-MS (Bruker Daltonics, Bremen, Germany) as described previously (Chen et al., 2012). Briefly, $0.1 \mathrm{mg}$ of seeds were homogenized in liquid nitrogen, and then transferring the powder to a $2 \mathrm{~mL}$ centrifuge tube, followed by extraction with $500 \mu \mathrm{L}$ modified Bieleski solvent (methanol/water/formic acid, 15/4/1, v/v/v) was added to it and the mixture was incubated at $4^{\circ} \mathrm{C}$ for $12 \mathrm{~h}$. The stable isotope labeled ABA $\left(\left[{ }^{2} \mathrm{H}_{6}\right] \mathrm{ABA}, 50 \mathrm{ng} / \mathrm{g}\right)$ was added to each of the samples to serve as internal standards for the quantification. Then, the supernatants were sequentially passed through the tandem solid phase extraction (SPE) cartridges containing C18 adsorbent $(50 \mathrm{mg})$ and SAX adsorbent $(200 \mathrm{mg})$. Before SPE extraction, the tandem cartridges were pre-conditioned with $8 \mathrm{~mL} \mathrm{H}_{2} \mathrm{O}, 8 \mathrm{~mL}$ methanol, and $8 \mathrm{~mL}$ modified Bieleski solvent. After sample loading, the $\mathrm{C} 18$ cartridge was removed and the SAX cartridge was rinsed with $2 \mathrm{~mL}$ methanol/ $\mathrm{H}_{2} \mathrm{O}(20 / 80$, $\mathrm{v} / \mathrm{v}$ ). After that, $3 \mathrm{~mL}$ acetonitrile (CAN) with $1 \%$ Hydrofluoric acid (FA) (v/v) was applied to elute the targeted ABA and the eluent was evaporated under mild nitrogen stream at $35^{\circ} \mathrm{C}$ followed by re-dissolving in $100 \mu \mathrm{L} \mathrm{H}_{2} \mathrm{O}$. The resulting solution $(100 \mu \mathrm{L})$ was then acidified with $10 \mu \mathrm{L} \mathrm{FA}$, and extracted with ether $(2 \times 1 \mathrm{~mL})$. The ether phase was combined,dried under nitrogen gas and reconstituted in $100 \mu \mathrm{L}$ ACN. To the resulting solution, $10 \mu \mathrm{L}$ triethylamine (TEA) $(20 \mu \mathrm{mol} / \mathrm{mL})$ and $10 \mu \mathrm{L} 3$ - Bromoactonyltrimethylammonium bromide (BTA) $(20 \mu \mathrm{mol} / \mathrm{mL})$ were added. The reaction solution was vortexed 
for $30 \mathrm{~min}$ at $35^{\circ} \mathrm{C}$ and evaporated under nitrogen gas followed by re-dissolving in $200 \mu \mathrm{L} \mathrm{H}_{2} \mathrm{O} / \mathrm{ACN}(90 / 10$, v/v) for instrumental analysis. The calibration curve was constructed by comparing peak area ratio (analyte/IS) to concentrations. The content of ABA was calculated according to the calibration curve. Three biological replicates were conducted.

\section{SUPEROXIDE DISMUTASE AND CATALASE ACTIVITY ASSAYS}

Total superoxide dismutase (SOD) activity was measured using a commercial WST-1 kit (S0102, Beyotime) following manufacturer's protocol. Briefly, seeds were powdered using liquid nitrogen and then homogenized in phosphate balanced solution buffer (PBS, pH7.5). The mixture was centrifuged at 12,000 $\times g$ at $4{ }^{\circ} \mathrm{C}$ for $15 \mathrm{~min}$. The supernatant thus obtained was used for the SOD activity measurement. The principle of this method lied on the coupling of 2-(4-iodophenyl)-3-(4-nitrophenyl)-5-(2, 16 4-disulfophenyl)-2H-tetrazolium (WST-1) with xanthine oxidase (XO) to generate $\mathrm{O}^{2-}$ and formazan dye, which can be inhibited by SOD through catalyzing $\mathrm{O}^{2-}$ into $\mathrm{H}_{2} \mathrm{O}_{2}$ and $\mathrm{O}_{2}$. SOD activity can be calculated by determining the absorbance of formazan dye at $450 \mathrm{~nm}$.

Catalase (CAT) activity was assayed using commercial kit (S0051, Beyotime) as described previously (Shi et al., 2012). Briefly, $10 \mu \mathrm{L}$ of $250 \mathrm{mM} \mathrm{H} \mathrm{O}_{2}$ was mixed with $5 \mu \mathrm{L}$ of protein supernatant. The $\mathrm{H}_{2} \mathrm{O}_{2}$ was decomposed by CAT for $5 \mathrm{~min}$, and the remaining $\mathrm{H}_{2} \mathrm{O}_{2}$ coupled with a substrate was treated with peroxidase (POD) to generate $\mathrm{N}$-4-antipyryl-3-chloro-5sulfonate-p-benzoquinonemonoimine. CAT activity was determined by calculating the decomposition rate of $\mathrm{H}_{2} \mathrm{O}_{2}$ at $520 \mathrm{~nm}$. Both enzymes were assayed for three replicates.

\section{PROTEIN EXTRACTION AND TWO-DIMENSIONAL ELECTROPHORESIS}

Proteins were extracted from B. napus seeds at 0 and $18 \mathrm{~h}$ after imbibition according to the method described previously (Chi et al., 2010). Briefly, $0.2 \mathrm{~g}$ of seeds were homogenized in ice-cold buffer containing $20 \mathrm{mM}$ Tris- $\mathrm{HCl}$ ( $\mathrm{pH} 7.5$ ), $250 \mathrm{mM}$ sucrose, $10 \mathrm{mM}$ ethylenebis(oxyethylenenitrilo) tetraacetic acid (EGTA), $1 \mathrm{mM}$ phenylmethanesulfonyl fluoride (PMSF), $1 \mathrm{mM}$ DL-dithiothreitol (DTT), and 1\% Triton X-100. The homogenate was centrifuged at $12000 \times g$ for $30 \mathrm{~min}$ at $4^{\circ} \mathrm{C}$. The supernatant was mixed with isometric Tris-Phenol ( $\mathrm{pH} 7.8)$ and vortexed for $20 \mathrm{~min}$. Mixture was then centrifuged at 12000 $\times g$ for $15 \mathrm{~min}$ at $4^{\circ} \mathrm{C}$. After centrifugation, the supernatant phenol phase and intermediate denatured protein layer were collected. Phenol phase containing proteins was then mixed with 5 volumes of $0.1 \mathrm{M}$ ammonium acetate in methanol and incubated at $-20^{\circ} \mathrm{C}$ overnight. Pellet, obtained after centrifugation at $12000 \times g$ for $30 \mathrm{~min}$, was washed 4 times with ice-cold acetone and vacuum dried. For two-dimensional electrophoresis (2-DE), the dried proteins pellets were dissolved in rehydration buffer containing $7 \mathrm{M}$ urea, $2 \mathrm{M}$ thiourea, $4 \%$ 3-[(3-Cholamidopropyl)dimethylammonio]propanesulfonate (CHAPS), 0.2\% carrier ampholyte, and $65 \mathrm{mM}$ DTT, and quantified according to Bradford's method (Bradford, 1976; Kruger, 1994). A total of $600 \mu \mathrm{g}$ of proteins of each sample were loaded on $17 \mathrm{~cm}$ IPG strip by rehydration loading for $12 \mathrm{~h}$ at room temperature. Based on primary screening, the IPG strips with $\mathrm{pH}$
5-8 (linear) were selected in this study. Isoelectric focusing (IEF) was carried out at 200,500, and $8000 \mathrm{~V}$ for $1,1.5$, and $10.5 \mathrm{~h}$, respectively (He et al., 2011). After IEF, the strips were incubated in equilibration buffer containing $0.05 \mathrm{M}$ Tris- $\mathrm{HCl} \mathrm{pH} 6.8,2.5 \%$ SDS, $10 \%(\mathrm{v} / \mathrm{v})$ glycerol and $2 \%$ DTT and shaken for $15 \mathrm{~min}$, and then for another $15 \mathrm{~min}$ with the iodoacetamide replaced DTT equilibration buffer. The second-dimensional separation of the proteins was carried out on 12\% SDS-PAGE (Li et al., 2012).

\section{GEL STAINING, SCANNING AND ANALYSIS}

The gels were stained with Coomassie brilliant blue-red (CBB-R) 250 for $40 \mathrm{~min}$, and then destained with $20 \%$ ethanol containing 10\% acetic acid. The destained gels were scanned using Epson Perfection $^{\mathrm{TM}}$ V700 Photo scanner (Epson, China Co., Ltd.) at 800 dots per inch (dpi) resolution. The transparency mode was used to obtain a gray scale image. The images were digitized and analyzed with PDQuest ${ }^{\mathrm{TM}}$ 2-DE Analysis Software 8.0 (BIO-RAD, CA, USA). The relative volume of each spot, which is defined as is the ratio between the volume of the given spot and the total volume of all the spots displaying on the gel, was used to represent the corresponding protein abundance. To obtain reproducible result, three biological repeat experiments were conducted. All the 12 gels were digitized separately. Automatic matching between different gels was conducted with four spots as internal standards. After that, manual adjustment was carried out to avoid mismatching. Spots which were detected in all the three replicates were used for comparative analysis. The spots showing more than 2-fold changes in abundance were defined as differentially displayed protein spots.

\section{IDENTIFICATION OF PROTEINS THROUGH MALDI -TOF/ TOF MS}

Differentially displayed protein spots were excised from the gels and distained using $50 \mathrm{mM} \mathrm{NH}_{4} \mathrm{HCO}_{3}$ in $50 \%(\mathrm{v} / \mathrm{v}) \mathrm{ACN}$. After complete de-staining, excised spots were first dehydrated using $50 \mu \mathrm{L} 100 \% \mathrm{ACN}$ and then rehydrated with 10 pmol trypsin in $25 \mathrm{mM} \mathrm{NH}_{4} \mathrm{HCO}_{3}$ at $4^{\circ} \mathrm{C}$ for $1 \mathrm{~h}$. Trypsin digestion was carried out at $37^{\circ} \mathrm{C}$ overnight. After digestion, the peptides were extracted according to the method described before (Yang et al., 2007). The collected peptides were desalted and analyzed with an ultrafleXtreme Matrix-Assisted Laser Desorption/ Ionization tandem Time of Flight (MALDI-TOF/TOF) mass spectrometer (Bruker, Germany) in a MS-MS mode. All the parameters were set to default. Briefly, $0.5 \mathrm{kHz}$ laser with $40 \mathrm{k}$ resolution was applied. The flexAnalysis software (Bruker) was used to generate the peak lists and process the MS and MS/MS spectra, which were searched against NCBInr (containing 15823071 sequences and 5433757279 residues) and Swiss-Prot databases (containing 138011 sequences from B. napus) using MASCOT as a search engine (Mascot Wizard 1.2.0, Matrix Science Ltd.) through BioTools (version 3.2) interface. The search parameters were set as follows: taxonomy, Viridiplantae; fixed modifications, carbamidomethylation; variable modification, methionine oxidation; MS tolerance, $50 \mathrm{ppm}$; MS/MS tolerance, 0.5 Da, peptide mass, monoisotopic. Only the significant hits $(p<0.01)$ with peptide scores $>45$ were accepted.

\section{STATISTICAL ANALYSIS}

The statistical analyses were carried out using Student's $t$-test when only two groups were compared, or with One-Way ANOVA 
followed by Tukey's multiple comparisons test for all other comparisons based on the three independent replicates.

\section{RESULTS}

\section{DETERMINATION OF SUITABLE ARTIFICIAL AGING TREATMENTS}

Mature seeds of $B$. napus gradually lose their viability during long term storage, which is defined as natural aging. To better understand the process of natural aging, germination percentages of 1 year aged seeds and freshly harvested seeds were calculated. Freshly harvested seeds started germination just after $6 \mathrm{~h}$ of imbibition and took less than $12 \mathrm{~h}$ for $50 \%$ percent of the seeds to germinate (Figure 1). In contrast, germination of the aged seeds was clearly delayed (Figure 1). It took about $30 \mathrm{~h}$ for the 1 year aged seeds to achieve $50 \%$ germination. In-spite of delayed germination of the aged seeds, most of the seeds were still able to germinate. Based on these results, we concluded that these seeds were at the early stage of natural aging and thus could be used as criterion to determine the suitable artificial aging treatments.

The fresh harvested seeds were exposed to $40^{\circ} \mathrm{C}$ and $90 \%$ relative humidity for $0,12,24$, and $48 \mathrm{~h}$ and viability of each seed sample was checked using germination assays (Figure 1). The treatment apparently declined the seed germination rate with increasing exposure time (Figure 1). For the sake of comparison, sample with similar germination rate with the natural aged control was selected for further study. Based on this criterion, $24 \mathrm{~h}$ of treatment (Figure 1) was determined as suitable artificial aging treatment as its germination rate was almost similar to that of natural aged seeds. Hereafter, treatment with $40^{\circ} \mathrm{C}$ and $90 \%$ relative humidity for 0 and $24 \mathrm{~h}$ is defined as control (CK) and CDT treatment, respectively in the rest of the manuscript.

\section{EFFECTS OF ARTIFICIAL AGING ON PHYSIO-BIOCHEMICAL STATUS OF B. NAPUS SEED}

As mentioned above, plasma membrane could be damaged during aging (Lee et al., 2012; Parkhey et al., 2012), therefore, in

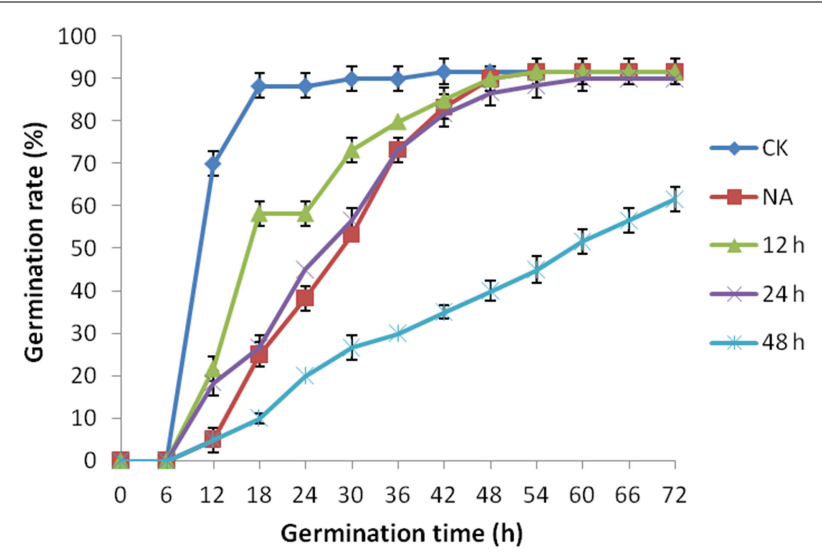

FIGURE 1 | The effect of artificial aging treatments on Brassica napus seed germination. CK and NA stand for the control and natural aged seeds (stored for 1 year). And 12, 24, and $48 \mathrm{~h}$ stand for seeds subjected to artificially aging treatments with $40^{\circ} \mathrm{C}$ and $90 \%$ relative humidity for 12,24 , and $48 \mathrm{~h}$ respectively. order to test the integrity of the membranes, relative ion leakage of CK and CDT samples at $0 \mathrm{~h}$ of imbibition were measured. The CDT samples showed approximately 1.8 fold higher ion leakage than the $\mathrm{CK}$ samples, indicating higher membrane damage in the former sample (Figure 2). Moreover, MDA content measurements of CK and CDT seeds also showed an increased MDA in the CDT seeds (Figure 2), further suggesting the increased membrane damage in the CDT seeds. Besides ion-leakage and MDA content measurements, we also measured the concentrations of $\mathrm{H}_{2} \mathrm{O}_{2}$ and $\mathrm{O}^{-}$, which are considered the two major ROS in plants. Surprisingly, the concentrations of both $\mathrm{H}_{2} \mathrm{O}_{2}$ and $\mathrm{O}^{-}$ were found to be similar in CK and CDT samples, indicating that increased ROS concentration might not be a necessary event during seed aging of B. napus seeds (Figure 3A). A gradual decrease in the concentration of ROS was observed during seed germination (Figure 3A). However, the decrease of ROS in the artificial aged seeds was much slower as compared to the control sample (Figure 3A), which might explain why the germination in aged seeds was delayed. Consistent with the changes in the ROS concentrations, the activities of the antioxidant enzymes, SOD, and CAT, were also dramatically declined in the artificially aged seeds before germination (Figure 3B).

\section{CHANGES IN THE PROTEOME OF B. NAPUS SEEDS EXPOSED TO ARTIFICIAL AGING TREATMENT}

To further explore the molecular mechanisms underlying the loss of seed vigor due to artificial aging treatments; comparative proteomic analysis was carried out. Based on the germination assay result, CK and CDT seeds showed obvious difference in germination rate at $18 \mathrm{~h}$ of imbibitions (Figure 1), so proteins were isolated from the $B$. napus seeds at $0 \mathrm{~h}$ and $18 \mathrm{~h}$ after imbibition respectively. The proteins will then be resolved on 2-D PAGE and stained with CBB R-250. Three independent replicates were performed for each sample (Figures 4, S2). After staining, the gels were scanned and digitized for the comparison. Analysis of the 2-DE gels was conducted with PDQuest ${ }^{\mathrm{TM}} 2$-DE Analysis software (version 8.0). Combined the biological replicates showed that there were about 600 reproducible protein spots (550-600) on each gel. A comparison of the 2-DE gels showed a total of 81 differentially accumulated spots (more then 2-fold changes in abundance) between CK and CDT samples, of which 36 and 48 were from 0 to $18 \mathrm{~h}$ of imbibition respectively. Three spots were common at both time points of imbibition.

To know if any of these differentially accumulated spots were involved in the seed aging process, these were excised from the gels, digested with trypsin and subjected to MALDITOF/TOF MS analysis. Based on the criteria described in materials and methods, 49 protein spots were successfully identified (Supplemental Table S1). Among these, seven spots were identified as two proteins, which resulted in the identification of a total of 54 distinct proteins (Table 1, Figure S3). Of these identified proteins, 15 proteins were only with the B. napus EST accession number. The sequences of these proteins were blasted against Arabidopsis database to gain a better understanding of their functions (Table 2). For many identified proteins, there were differences between their experimental and theoretical pI and molecular weight. Several possibilities may help to explain 

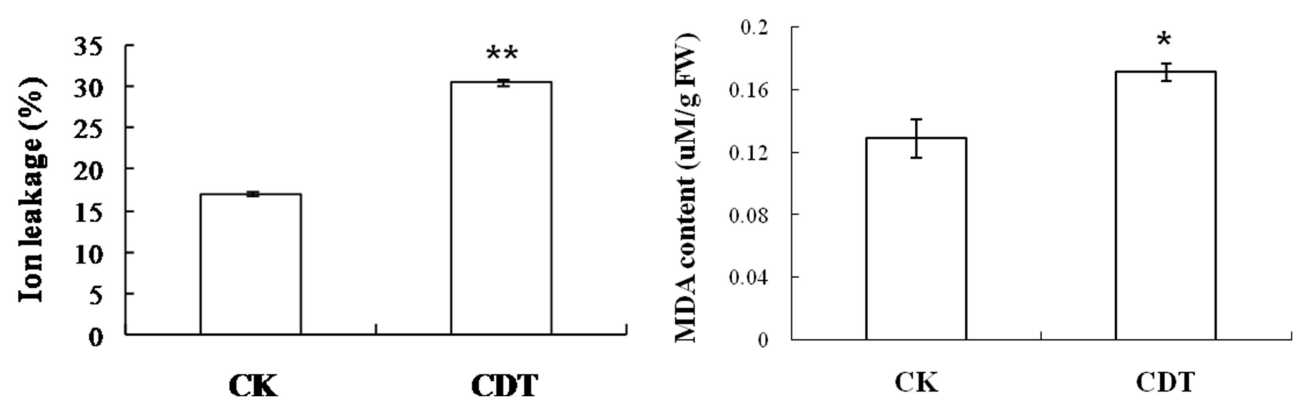

FIGURE 2 | The effect of CDT on the ion leakage and MDA content in the seeds at $\mathbf{0} \mathbf{h}$ of germination. Values are the means $\pm \mathrm{SE}$ from three biological replicates. ${ }^{*}$ and ${ }^{* *}$ indicate significant difference at $P<0.05$ and 0.01 respectively.

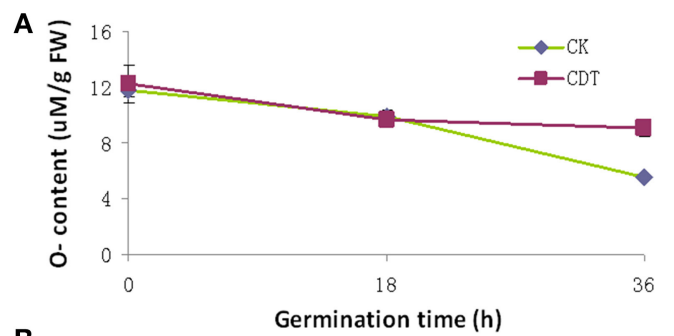

B

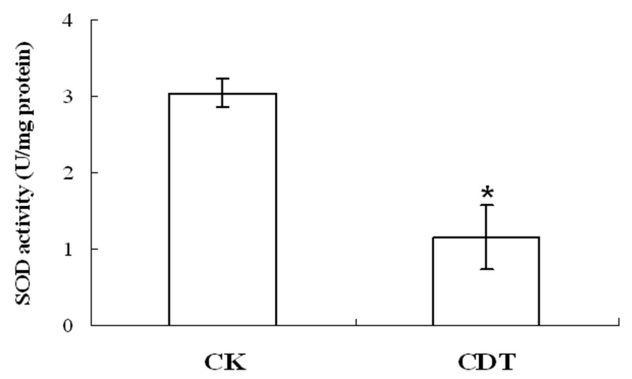

FIGURE 3 | The effects of CDT on the ROS homeostasis. (A) ROS content, including $\mathrm{O}^{-}$(left panel) and $\mathrm{H}_{2} \mathrm{O}_{2}$ (right panel). (B) Changes in the SOD (left panel) and CAT (right panel) activity during
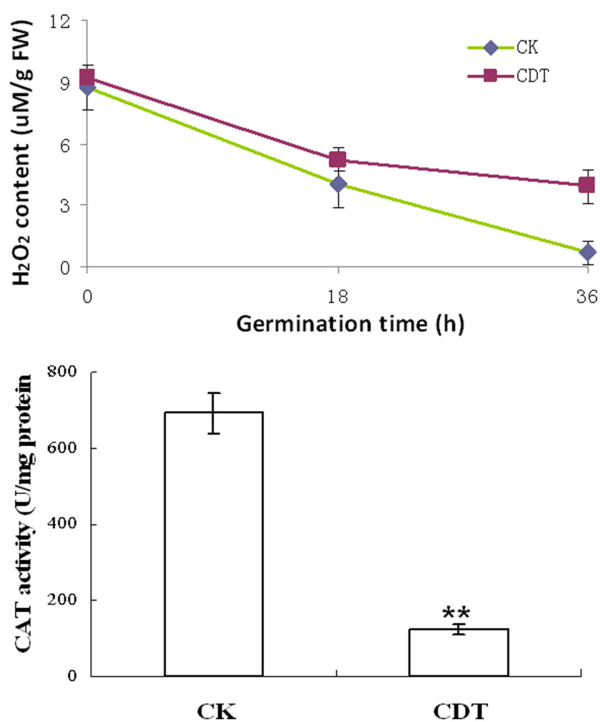

germination. Values are the means \pm SE from three biological replicates. $*$ and $* *$ indicate significant difference at $P<0.05$ and 0.01 respectively. this result. First, the genome of $B$. napus is not fully sequenced and annotated, which might result in deviation; second, some of the proteins might be subjected to post-translational modifications or cleavage. MapMan ontology analysis (Thimm et al., 2004) sorted all the identified proteins into 10 functional groups including metabolism, protein destination, stress response, redox homeostasis, development, hormones related, cell structure, miscellaneous enzymes, storage proteins, and function unassigned proteins (Table 1, Figure 5).

\section{EFFECTS OF ABA AND GA ON THE SEED AGING}

As no major differences in the ROS concentrations and antioxidant enzymes activities were observed after CDT treatment, we speculated that oxidative stress is not the major factor involved in the inhibition of germination after CDT treatment. Therefore, involvement of some other factors, which resulted in delayed germination after CDT treatment, was expected. Among all the external and internal factors, ABA seems to be the most important one which inhibits seed germination. Therefore, we measured the ABA content of the CK and CDT seeds at both 0 and $18 \mathrm{~h}$ after imbibition. Interestingly, the ABA content of the CDT seeds was much higher than that observed in the CK seeds at both the time points, and showed a sharp decrease upon imbibition in both the samples (Figure 6), suggesting involvement of ABA in seed aging. To further confirm this hypothesis, the CK seeds were germinated in the presence of $\mathrm{ABA}$, and showed a delayed germination (Figure 7). It is known that GA and ABA play antagonistic roles in regulating seed germination, so we also germinated the CDT seed in the presence of GA to see if this treatment can recover its germination phenotype or not. Consistently, GA treated CDT seeds showed partially recovered germination (Figure 7).

\section{DISCUSSION}

Temperature and moisture content (relative humidity) are two important environmental factors that influence seed aging. High temperature and moisture accelerate the process of seed aging, 


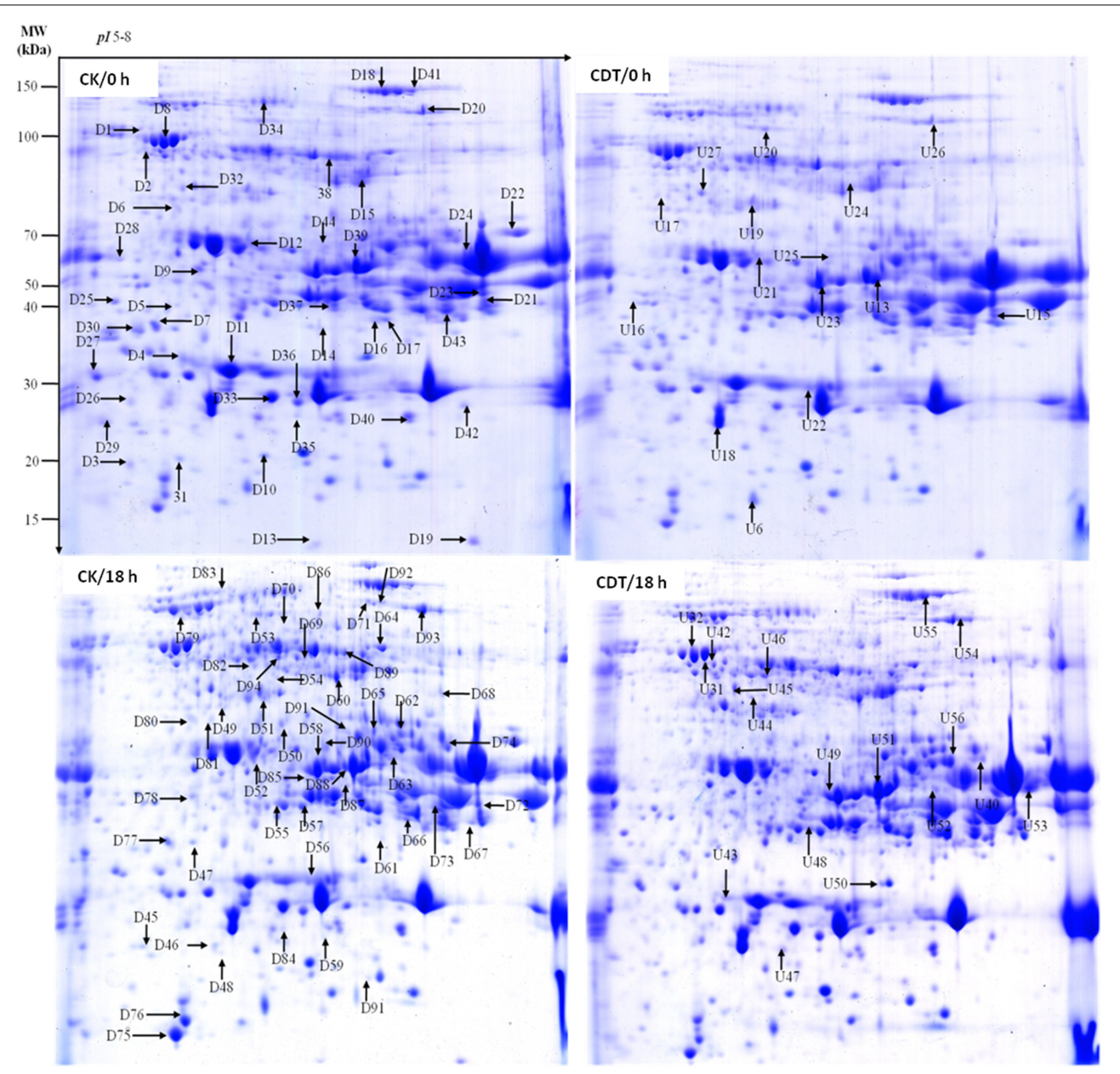

FIGURE 4 | Representative two-dimensional gel images of Brassica napus seeds. Gels are from both control (left panel) and treated (right panel) seeds at 0 and $18 \mathrm{~h}$ after imbibition. Arrows show the differentially displayed protein spots, $\mathrm{D}$ and $\mathrm{U}$ stands for down-regulated and up-regulated proteins, respectively.

leading to the rapid loss of seed vigor. The accelerated aging has been applied as an indicator of crop seed storability (Priestley, 1986). To study the mechanism of seed aging, researchers have developed the accelerated aging protocol in laboratory by exposing the seeds to high temperature and humidity conditions (Job, 2005; El-Maarouf-Bouteau et al., 2011). ROS have been presumed as the main factors which lead to the seed aging during storage (Bailly et al., 1996; Bailly, 2004; Kibinza et al., 2006; Parkhey et al., 2012). In order to understand the mechanisms underlying $B$. napus seed aging, especially at the initiation stage, we subjected the $B$. napus seeds with CDT, which obviously delayed the germination and slightly decreased the germination rate which was similar to the 1 year naturally aged seeds (Figure 1). These results suggested that this treatment was suitable for further analysis as it could mimic the physiology of 1 year naturally aged seeds.

The CDT resulted in the increased ion leakage (Figure 2), which reflects the damages of cellular membranes. This damage, in turn, resulted in the accumulation of MDA in the CDT seeds (Figure 2). Previously, it was considered that attack of ROS on membranes might be one of the reasons that lead to the ion leakage (Leymarie et al., 2012). Furthermore, previous study also showed that high temperature and humidity drastically increased the extent of protein oxidation in Arabidopsis seeds (Rajjou et al., 2008). However, after the CDT in the B. napus seeds, we did not detect any over accumulation of ROS (Figure 3A), and any differentially accumulated antioxidant enzymes except for peroxiredoxin (Table 1). Since only about 500 proteins were detected, it could not be absolutely excluded that there were some antioxidant enzymes changed. In spite of this, CDT did decrease the rate of ROS detoxification during germination (Figure 3A), suggesting that artificial aging might disturb the ROS scavenging system. This result was also supported by the decline of SOD and CAT activities (Figure 3B). The CDT might decrease the activities of the antioxidant enzymes because of the high temperature, since most of the enzymes have their highest activities at around $35^{\circ} \mathrm{C}$ under physiological conditions.

Functional classification of the identified proteins showed that proteins related to protein modification and destination, development and cell structure were differentially modulated after CDT. However, previous studies on pea (Barba-Espin et al., 2011) and wheat seeds (Bykova et al., 2011) have shown that $\mathrm{H}_{2} \mathrm{O}_{2}$ treatment preferentially regulates proteins majorly involved in redox 
Table 1 | Identification of the differentially displayed proteins in rapeseeds exposed to artificial aging treatment.

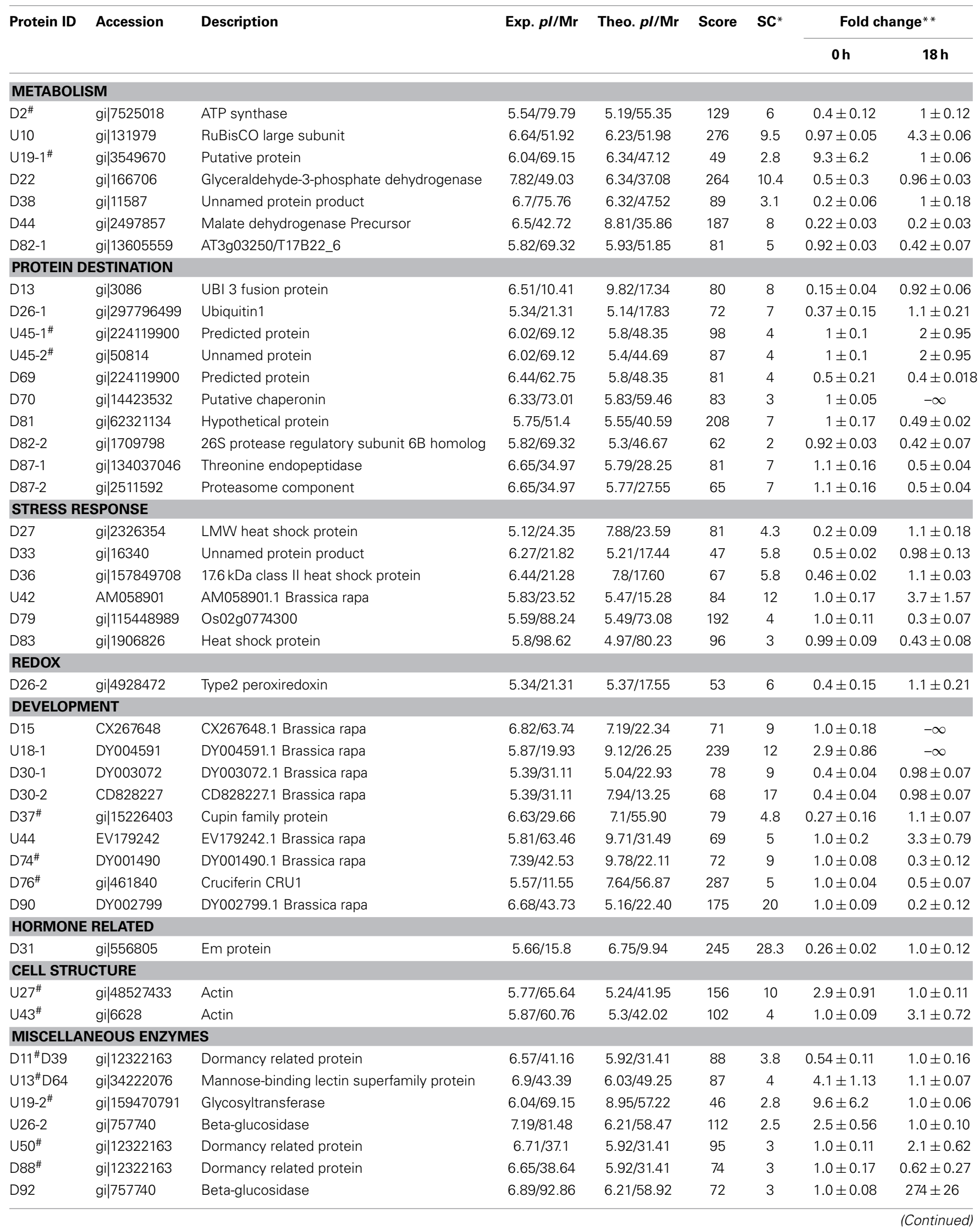


Table 1 | Continued

\begin{tabular}{|c|c|c|c|c|c|c|c|c|}
\hline Protein ID & Accession & Description & Exp. pl/Mr & Theo. $p l / M r$ & Score & SC* & \multicolumn{2}{|c|}{ Fold change ${ }^{* *}$} \\
\hline D37 & gi|15226403 & Cupin family protein & $6.63 / 29.66$ & $7.1 / 55.90$ & 79 & 4.8 & $0.5 \pm 0.16$ & $1.0 \pm 0.11$ \\
\hline U41 & gi|167136 & Cruciferin precursor & $5.68 / 72.89$ & $6.84 / 56.43$ & 92 & 3 & $0.99 \pm 0.08$ & $2.5 \pm 0.01$ \\
\hline D75 & gi|166678 & $12 \mathrm{~S}$ storage protein $\mathrm{CRB}$ & $5.5 / 10.82$ & $6.77 / 50.95$ & 158 & 3 & $0.98 \pm 0.11$ & $0.56 \pm 0.07$ \\
\hline \multicolumn{9}{|c|}{ UNASSIGNED } \\
\hline D7 & DY002554 & DY002554.1 Brassica rapa & $5.46 / 31.37$ & $8.71 / 16.29$ & 231 & 22 & $0.46 \pm 0.03$ & $0.43 \pm 0.07$ \\
\hline U18-2 & DY002789 & DY002789.1 Brassica rapa & $5.87 / 19.93$ & $9.35 / 24.44$ & 205 & 14 & $2.9 \pm 0.39$ & $-\infty$ \\
\hline D41 & DY002558 & DY002558.1 Brassica rapa & $7.2 / 110.01$ & $5.29 / 24.81$ & 78 & 8 & $0.4 \pm 0.20$ & $1.0 \pm 0.08$ \\
\hline U48 & CX278338 & CX278338.1 Brassica rapa & $6.4 / 38.37$ & $9.03 / 27.20$ & 276 & 18 & $0.99 \pm 0.15$ & $2.5 \pm 0.64$ \\
\hline
\end{tabular}

* SC stands for sequence coverage.

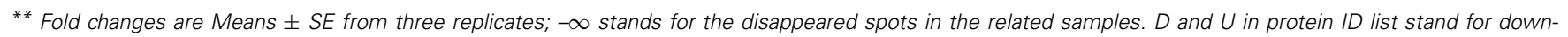
regulated protein and up-regulated protein respectively.

\# Indicates these proteins were statistically not but manually checked to be differentially expressed.

Table 2 | Blast of the identified proteins through searching against Brassica napus EST database.

\begin{tabular}{|c|c|c|c|c|c|c|}
\hline Protein ID & Accession no. & AGI No. & Description & Score & Identity (\%) & $\begin{array}{l}\text { Functional } \\
\text { group }\end{array}$ \\
\hline D7 & DY002554 & AT2G42560 & LEA domain-containing protein & 79 & 47 & Unassigned \\
\hline D15 & CX267648 & AT2G36640 & Embryonic cell protein 63 & 164 & 51 & Development \\
\hline D30-1 & DY003072 & AT2G28490 & RmlC-like cupins superfamily protein & 266 & 76 & Development \\
\hline D30-2 & CD828227 & AT2G28490 & RmIC-like cupins superfamily protein & 79 & 63 & Development \\
\hline D41 & DY002558 & AT2G42560 & LEA domain-containing protein & 172 & 55 & Unassigned \\
\hline D58 & DY001351 & AT5G45690 & Protein of unknown function (DUF1264) & 369 & 82 & Unassigned \\
\hline D74 & DY001490 & AT3G22640 & Cupin family protein & 185 & 68 & Development \\
\hline D71 & DY002554 & AT2G42560 & LEA domain-containing protein & 78.6 & 47 & Unassigned \\
\hline D78 & DY002558 & AT2G42560 & LEA domain-containing protein & 172 & 55 & Unassigned \\
\hline D90 & DY002799 & AT3G22640 & Cupin family protein & 290 & 70 & Development \\
\hline U18-1 & DY004591 & AT1G03890 & RmlC-like cupins superfamily protein & 299 & 78 & Development \\
\hline U18-2 & DY002789 & AT5G01300 & PEBP (phosphatidylethanolamine- binding protein) family protein & 302 & 85 & Unassigned \\
\hline U42 & AM058901 & AT2G21060 & Glycine-rich protein 2B & 145 & 84 & Stress \\
\hline U44 & EV179242 & AT3G53040 & LEA domain-containing protein & 117 & 52 & Development \\
\hline U48 & CX278338 & AT5G45690 & Protein of unknown function (DUF1264) & 277 & 82 & Unassigned \\
\hline
\end{tabular}

homeostasis, metabolism, hormones related and RNA related, and it could invoke the changes of proteins with similar functions in different tissues (Wan and Liu, 2008; Zhou et al., 2011). The differences in the differentially accumulated proteins in this study with the previously published reports on pea and wheat, suggest that the seed aging mechanism in the B. napus seeds is quite different with that indicating in case of pea and wheat seeds. Our results suggest that CDT treatment might initiate the aging of $B$. napus seeds through enhancing the biosynthesis of germination inhibitors and lately through the accumulation of ROS. Although there were 81 differentially accumulated proteins between CK and CDT seeds, only 49 spots were successfully identified. The identification rate is just about $60 \%$, which might be explained by the un-sequenced genome of $B$. napus. Moreover, there seven spots were identified as two different proteins, which should result in difficulties to evaluate a real abundance of each protein within them. This is one of the limitations in 2-D gel based proteomic techniques. Future studies with gel-free systems might help to provide more information.

Since the CDT treatment delayed the germination not primarily because of accumulation of ROS, we speculated that there should be some other mechanisms which mediate the seed aging process in B. napus seeds. Among the identified proteins, most of the proteins involved in metabolism and protein destination were 

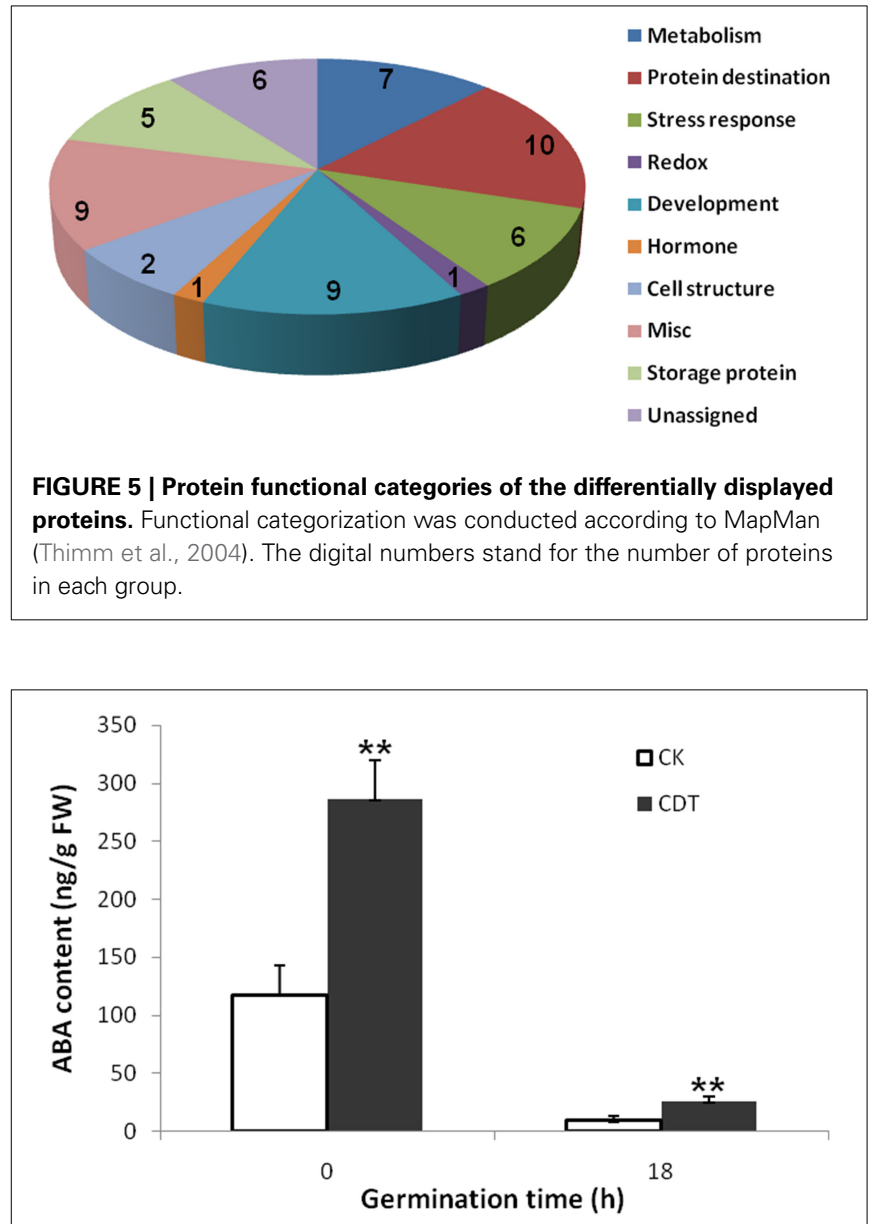

FIGURE 6 | Contents of ABA in Brassica napus seeds exposed to CDT treatment during germination. Values are the means \pm SE from three biological replicates. ${ }^{* *}$ indicate significant difference at $P<0.01$.

decreased in the CDT seeds. These results indicate that the basic biological activities might be inhibited by the CDT treatment, which would result in the delayed germination. Interestingly, rubisco large subunit was increased in the CDT treated seed at $18 \mathrm{~h}$ after germination, which indicates the existence of feedback regulation. In contrast to the metabolism and protein destination related proteins, many cell structural proteins and miscellaneous enzymes, such as actin, mannose-binding lectin superfamily protein, glycosyltransferase, beta-glucosidase, were increased. All these proteins are related to the cell and cell wall structures. It might be interesting to know how these proteins affect seed aging.

Among all the internal factors, ABA has been reported to be one of the main factor that inhibits the seed germination (Gubler et al., 2005; Finch-Savage and Leubner-Metzger, 2006; Penfield et al., 2006). Measurements of the ABA content in B. napus seeds showed that there was a sharp increase of ABA content in the CDT treated seeds (Figure 6). Although the ABA was degraded during the germination, its concentration was still higher in the CDT treated seeds in comparison with the CK seeds (Figure 6). Furthermore, imbibition of the CK seeds with ABA solution showed delayed germination (Figure 7). Germination of the CDT treated seeds was partially recovered after the GA treatment,

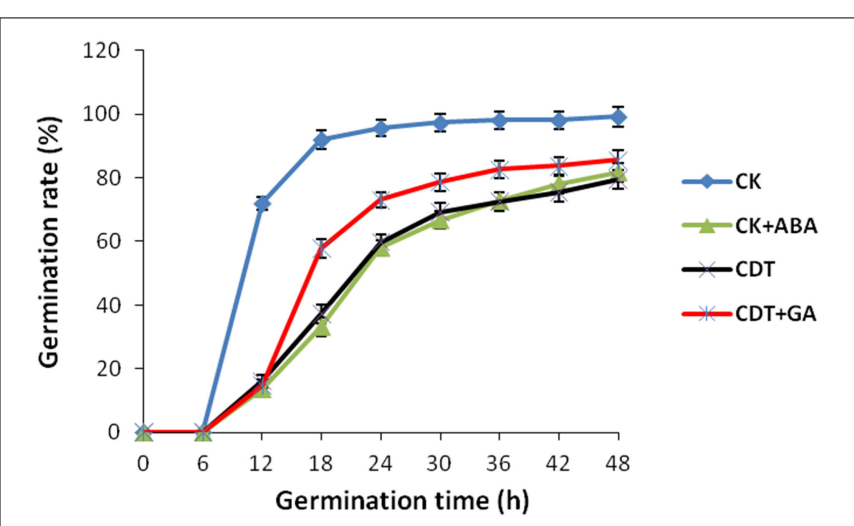

FIGURE 7 | Effects of ABA and GA on Brassica napus seed germination. Values are the means \pm SE from three biological replicates.

further confirming the involvement of $\mathrm{ABA}$ in the inhibition of seed germination during aging. However, how this ABA concentration is increased during aging treatment in the B. napus seeds, is still elusive. Unfortunately, we did not detect any changes of the enzymes involved in the ABA biosynthesis and degradation. It is well known that ABA is synthesized in the seeds during desiccation which allow the survival of seeds in dry state (Tan et al., 1997; Nakabayashi et al., 2005). During this process, genes involved in ABA biosynthesis were found to be highly expressed, and corresponding enzymes were abundantly accumulated. Based on these results, we suggest that exposure of seeds with high humidity and temperature might partly recover the activities of the ABA biosynthesis enzymes which results in the enhanced production of ABA in the B. napus seeds during aging.

\section{AUTHOR CONTRIBUTIONS}

YX did the experiments; HD prepared the seeds and analyzed some of the data; YP designed the experiments and wrote the manuscript.

\section{ACKNOWLEDGMENTS}

The authors are grateful to Ms Tingting Li from Institute of Hydrobiology, Chinese Academy of Sciences for the assistance in MALDI-TOF/TOF MS analysis. This work was supported by the National Natural Science Foundation of China (NSFC, No. 31271805), 100 talents program of Chinese Academy of Sciences, and Sino-Africa Joint Research Project (SAJC201324).

\section{SUPPLEMENTARY MATERIAL}

The Supplementary Material for this article can be found online at: http://www.frontiersin.org/journal/10.3389/fpls.2015. 00112/abstract

Table S1 | Identification of the differentially expressed proteins.

\section{REFERENCES}

Bailly, C. (2004). Active oxygen species and antioxidants in seed biology. Seed Sci. Res. 14, 93-107. doi: 10.1079/SSR2004159

Bailly, C., Benamar, A.,Corbineau, F., and Come, D. (1996). Changes in malondialdehyde content and in superoxide dismutase, catalase and glutathione reductase activities in sunflower seeds as related to deterioration during accelerated aging. Physiol. Plant. 97, 104-110. doi: 10.1111/j.1399-3054.1996. tb00485.x 
Barba-Espin, G., Diaz-Vivancos, P., Job, D., Belghazi, M., Job, C., and Hernandez, J. A. (2011). Understanding the role of $\mathrm{H}(2) \mathrm{O}(2)$ during pea seed germination: a combined proteomic and hormone profiling approach. Plant Cell Environ. 34, 1907-1919. doi: 10.1111/j.1365-3040.2011.02386.x

Bentsink, L., Jowett, J., Hanhart, C. J., and Koornneef, M. (2006). Cloning of DOG1, a quantitative trait locus controlling seed dormancy in Arabidopsis. Proc. Natl. Acad. Sci. U.S.A. 103, 17042-17047. doi: 10.1073/pnas.0607877103

Bewley, J. D. (1997). Seed germination and dormancy. Plant Cell 9, 1055-1066. doi: 10.1105/tpc.9.7.1055

Bradford, M. M. (1976). A rapid and sensitive method for the quantitation of microgram quantities of protein utilizing the principle of protein-dye binding. Anal. Biochem. 72, 248-254. doi: 10.1016/0003-2697(76)90527-3

Bykova, N. V., Hoehn, B., Rampitsch, C., Banks, T., Stebbing, J. A., Fan, T., et al. (2011). Redox-sensitive proteome and antioxidant strategies in wheat seed dormancy control. Proteomics 11, 865-882. doi: 10.1002/pmic.200900810

Chatelain, E., Satour, P., Laugier, E., Ly Vu, B., Payet, N., Rey, P., et al. (2013). Evidence for participation of the methionine sulfoxide reductase repair system in plant seed longevity. Proc. Natl. Acad. Sci. U.S.A. 110, 3633-3638. doi: 10.1073/pnas. 1220589110

Chen, M. L., Fu, X. M., Liu, J. Q., Ye, T. T., Hou, S. Y., Huang, Y. Q., et al. (2012). Highly sensitive and quantitative profiling of acidic phytohormones using derivatization approach coupled with nano-LC-ESI-Q-TOF-MS analysis. J. Chromatogr. B 905, 67-74. doi: 10.1016/j.jchromb.2012.08.005

Chi, F., Yang, P., Han, F., Jing, Y., and Shen, S. (2010). Proteomic analysis of rice seedlings infected by Sinorhizobium meliloti 1021. Proteomics 10, 1861-1874. doi: 10.1002/pmic.200900694

Clerkx, E. J., El-Lithy, M. E., Vierling, E., Ruys, G. J., Blankestijn-De Vries, H., Groot, S. P., et al. (2004). Analysis of natural allelic variation of Arabidopsis seed germination and seed longevity traits between the accessions Landsberg erecta and Shakdara, using a new recombinant inbred line population. Plant Physiol. 135, 432-443. doi: 10.1104/pp.103.036814

Corbineau, F., Gay-Mathieu, C., Vinel, D., and Côme, D. (2002). Decrease in sunflower (Helianthus annuus) seed viability caused by high temperature as related to energy metabolism, membrane damage and lipid composition. Physiol. Plant. 116, 489-496. doi: 10.1034/j.1399-3054.2002.1160407.x

Debeaujon, I., Leon-Kloosterziel, K. M., and Koornneef, M. (2000). Influence of the testa on seed dormancy, germination, and longevity in Arabidopsis. Plant Physiol. 122, 403-414. doi: 10.1104/pp.122.2.403

Ellis, R. (1992). Seed and seedling vigour in relation to crop growth and yield. Plant Growth Regul. 11, 249-255. doi: 10.1007/BF00024563

El-Maarouf-Bouteau, H., Mazuy, C., Corbineau, F., and Bailly, C. (2011). DNA alteration and programmed cell death during ageing of sunflower seed. J. Exp. Bot. 62, 5003-5011. doi: 10.1093/jxb/err198

Finch-Savage, W. E., and Leubner-Metzger, G. (2006). Seed dormancy and the control of germination. New Phytol. 171, 501-523. doi: 10.1111/j.14698137.2006.01787.x

Garza-Caligaris, L. E., Avendano-Vazquez, A. O., Alvarado-Lopez, S., ZunigaSanchez, E., Orozco-Segovia, A., Perez-Ruiz, R. V., et al. (2012). At3g08030 transcript: a molecular marker of seed ageing. Ann. Bot. 110, 1253-1260. doi: $10.1093 / \mathrm{aob} / \mathrm{mcs} 200$

Grant, J. J., and Loake, G. J. (2000). Role of reactive oxygen intermediates and cognate redox signalling in disease resistance. Plant Physiol. 124, 21-29. doi: 10.1104/pp.124.1.21

Gubler, F., Millar, A. A., and Jacobsen, J. V. (2005). Dormancy release, ABA and pre-harvest sprouting. Curr. Opin. Plant Biol. 8, 183-187. doi: 10.1016/j.pbi.2005.01.011

He, D., Han, C., and Yang, P. (2011). Gene expression profile changes in germinating rice. J. Integr. Plant Biol. 53, 835-844. doi: 10.1111/j.1744-7909.2011.01074.x

Holdsworth, M. J., Bentsink, L., and Soppe, W. J. (2008). Molecular networks regulating Arabidopsis seed maturation, after-ripening, dormancy and germination. New Phytol. 179, 33-54. doi: 10.1111/j.1469-8137.2008.02437.x

Jaw-Neng Lin, C. H. K. (1998). Effect of oxidative stress caused by hydrogen peroxide on senescence of rice leaves. Bot. Bull. Acad. Sin. 39, 161-165.

Job, C. (2005). Patterns of protein oxidation in arabidopsis seeds and during germination. Plant Physiol. 138, 790-802. doi: 10.1104/pp.105.062778

Kibinza, S., Vinel, D., Côme, D., Bailly, C., and Corbineau, F. (2006). Sunflower seed deterioration as related to moisture content during ageing, energy metabolism and active oxygen species scavenging. Physiol Plant. 128, 496-506. doi: 10.1111/j.1399-3054.2006.00771.x
Kruger, N. J. (1994). The Bradford method for protein quantitation. Basic Methods Mol. Biol. 32, 9-15.

Lee, J., Welti, R., Roth, M., Schapaugh, W. T., Li, J., and Trick, H. N. (2012). Enhanced seed viability and lipid compositional changes during natural ageing by suppressing phospholipase Dalpha in soybean seed. Plant Biotechnol. J. 10, 164-173. doi: 10.1111/j.1467-7652.2011.00650.x

Leymarie, J., Vitkauskaite, G., Hoang, H. H., Gendreau, E., Chazoule, V., Meimoun, P., et al. (2012). Role of reactive oxygen species in the regulation of Arabidopsis seed dormancy. Plant Cell Physiol. 53, 96-106. doi: 10.1093/pcp/pcr129

Li, M., Sha, A., Zhou, X., and Yang, P. (2012). Comparative proteomic analyses reveal the changes of metabolic features in soybean (Glycine max) pistils upon pollination. Sex. Plant Reprod. 25, 281-291. doi: 10.1007/s00497-012-0197-0

Miura, K., Lin, Y., Yano, M., and Nagamine, T. (2002). Mapping quantitative trait loci controlling seed longevity in rice (Oryza sativa L.). Theor. Appl. Genet. 104, 981-986. doi: 10.1007/s00122-002-0872-x

Nakabayashi, K., Okamoto, M., Koshiba, T., Kamiya, Y., and Nambara, E. (2005). Genome-wide profiling of stored mRNA in Arabidopsis thaliana seed germination: epigenetic and genetic regulation of transcription in seed. Plant J. 41, 697-709. doi: 10.1111/j.1365-313X.2005.02337.x

Neill, S., Desikan, R., and Hancock, J. (2002). Hydrogen peroxide signalling. Curr. Opin. Plant Biol. 5, 388-395. doi: 10.1016/S1369-5266(02)00282-0

Oge, L., Bourdais, G., Bove, J., Collet, B., Godin, B., Granier, F., et al. (2008). Protein repair L-isoaspartyl methyltransferase 1 is involved in both seed longevity and germination vigor in Arabidopsis. Plant Cell 20, 3022-3037. doi: $10.1105 /$ tpc. 108.058479

Parkhey, S., Naithani, S. C., and Keshavkant, S. (2012). ROS production and lipid catabolism in desiccating Shorea robusta seeds during aging. Plant Physiol. Biochem. 57, 261-267. doi: 10.1016/j.plaphy.2012. 06.008

Penfield, S., Li, Y., Gilday, A. D., Graham, S., and Graham, I. A. (2006). Arabidopsis, ABA INSENSITIVE4 regulates lipid mobilization in the embryo and reveals repression of seed germination by the endosperm. Plant Cell 18, 1887-1899. doi: $10.1105 /$ tpc. 106.041277

Priestley, D. A. (1986). Seed Aging: Implications for Seed Storage and Persistence in the Soil. New York, NY: Cornell University Press.

Prieto-Dapena, P., Castano, R., Almoguera, C., and Jordano, J. (2006). Improved resistance to controlled deterioration in transgenic seeds. Plant Physiol. 142, 1102-1112. doi: 10.1104/pp.106.087817

Rajjou, L., Duval, M., Gallardo, K., Catusse, J., Bally, J., Job, C., et al. (2012). Seed germination and vigor. Annu. Rev. Plant Biol. 63, 507-533. doi: 10.1146/annurev-arplant-042811-105550

Rajjou, L., Lovigny, Y., Groot, S. P. C., Belghazi, M., Job, C., and Job, D. (2008). Proteome-wide characterization of seed aging in Arabidopsis: a comparison between artificial and natural aging protocols. Plant Physiol. 148, 620-641. doi: 10.1104/pp.108.123141

Sattler, S. E., Gilliland, L. U., Magallanes-Lundback, M., Pollard, M., and DellaPenna, D. (2004). Vitamin E is essential for seed longevity and for preventing lipid peroxidation during germination. Plant Cell 16, 1419-1432. doi: $10.1105 /$ tpc. 021360

Shi, H., Wang, Y., Cheng, Z., Ye, T., and Chan, Z. (2012). Analysis of natural variation in bermudagrass (Cynodon dactylon) reveals physiological responses underlying drought tolerance. PLOS ONE 7:e53422. doi: 10.1371/journal.pone.0053422

Tan, B. C., Schwartz, S. H., Zeevaart, J. A., and McCarty, D. R. (1997). Genetic control of abscisic acid biosynthesis in maize. Proc. Natl. Acad. Sci. U.S.A 94, 12235-12240. doi: 10.1073/pnas.94.22.12235

Thimm, O., Blsing, O., Gibon, Y., Nagel, A., Meyer, S., Krüger, P., et al. (2004). MAPMAN: a user-driven tool to display genomics data sets onto diagrams of metabolic pathways and other biological processes. Plant J. 37, 914-939. doi: 10.1111/j.1365-313X.2004.02016.x

Verma, P., Kaur, H., Petla, B. P., Rao, V., Saxena, S. C., and Majee, M. (2013). PROTEIN L-ISOASPARTYL METHYLTRANSFERASE2 is differentially expressed in chickpea and enhances seed vigor and longevity by reducing abnormal isoaspartyl accumulation predominantly in seed nuclear proteins. Plant Physiol. 161, 1141-1157. doi: 10.1104/pp.112. 206243

Walters, C., Wheeler, L. M., and Grotenhuis, J. M. (2005). Longevity of seeds stored in a genebank: species characteristics. Seed Sci. Res. 15, 1-20. doi: 10.1079/SSR2004195 
Wan, X.-Y., and Liu, J.-Y. (2008). Comparative proteomics analysis reveals an intimate protein network provoked by hydrogen peroxide stress in rice seedling leaves. Mol. Cell. Proteomics 7, 1469-1488. doi: 10.1074/mcp.M700488-MCP200

Yang, P., Li, X., Wang, X., Chen, H., Chen, F., and Shen, S. (2007). Proteomic analysis of rice (Oryza sativa) seeds during germination. Proteomics 7, 3358-3368. doi: 10.1002/pmic.200700207

Zhou, L., Bokhari, S. A., Dong, C. J., and Liu, J. Y. (2011). Comparative proteomics analysis of the root apoplasts of rice seedlings in response to hydrogen peroxide. PLoS ONE 6:e16723. doi: 10.1371/journal.pone.0016723

Conflict of Interest Statement: The authors declare that the research was conducted in the absence of any commercial or financial relationships that could be construed as a potential conflict of interest.
Received: 11 September 2014; accepted: 11 February 2015; published online: 25 February 2015.

Citation: Yin X, He D, Gupta R and Yang P (2015) Physiological and proteomic analyses on artificially aged Brassica napus seed. Front. Plant Sci. 6:112. doi: 10.3389/fpls. 2015.00112

This article was submitted to Plant Proteomics, a section of the journal Frontiers in Plant Science.

Copyright (c) 2015 Yin, He, Gupta and Yang. This is an open-access article distributed under the terms of the Creative Commons Attribution License (CC BY). The use, distribution or reproduction in other forums is permitted, provided the original author(s) or licensor are credited and that the original publication in this journal is cited, in accordance with accepted academic practice. No use, distribution or reproduction is permitted which does not comply with these terms. 